\title{
Observational and model evidence of global emergence of permanent, unprecedented heat in the 20th and 21 st centuries
}

\section{A letter}

\author{
Noah S. Diffenbaugh $\cdot$ Martin Scherer
}

Received: 8 March 2011 / Accepted: 16 May 2011 / Published online: 7 June 2011

(C) The Author(s) 2011. This article is published with open access at Springerlink.com

\begin{abstract}
Given the severe impacts of extreme heat on natural and human systems, we attempt to quantify the likelihood that rising greenhouse gas concentrations will result in a new, permanent heat regime in which the coolest warm-season of the 21st century is hotter than the hottest warm-season of the late 20th century. Our analyses of global climate model experiments and observational data reveal that many areas of the globe are likely to permanently move into such a climate space over the next four decades, should greenhouse gas concentrations continue to increase. In contrast to the common perception that high-latitude areas face the most accelerated response to global warming, our results demonstrate that in fact tropical areas exhibit the most immediate and robust emergence of unprecedented heat, with many tropical areas exhibiting a $50 \%$ likelihood of permanently moving into a novel seasonal heat regime in the next two decades. We also find that global climate models are able to capture the observed intensification of seasonal hot conditions, increasing confidence in the projection of imminent, permanent emergence of unprecedented heat.
\end{abstract}

\section{Introduction}

Extreme heat exerts severe impacts on natural and human systems. These impacts are particularly acute in the areas of human health (Poumadere et al. 2005; Patz et al. 2005), agricultural production (White et al. 2006; Schlenker and Roberts 2009), and food security (Battisti and Naylor 2009), and in the most severe cases may also substantially reduce ecosystem productivity (Ciais et al. 2005).

Electronic supplementary material The online version of this article (doi:10.1007/s10584-011-0112-y) contains supplementary material, which is available to authorized users.

N. S. Diffenbaugh $(\bowtie) \cdot$ M. Scherer

Department of Environmental Earth System Science and Woods Institute for the Environment, Stanford University, 473 Via Ortega, Stanford, CA 94305-4216, USA

e-mail: diffenbaugh@stanford.edu 
Given the severity of these impacts, considerable attention has been given to understanding how hot extremes are likely to respond to elevated greenhouse forcing. This attention has generated ample evidence that continued increases in global greenhouse gas (GHG) concentrations are likely to result in increases in the occurrence and intensity of extreme hot events (Christensen et al. 2007), and that this intensification could substantially increase stress on heat-sensitive systems (e.g., Patz et al. 2005; White et al. 2006; Battisti and Naylor 2009). Indeed, the response of extreme temperature to enhanced radiative forcing is sufficiently strong to suggest that the " $2{ }^{\circ} \mathrm{C}$ " mitigation target agreed upon by the international community (UNFCCC 2009) is not likely to avoid intensification of severe hot events (Clark et al. 2010; Diffenbaugh and Ashfaq 2010), and that unconstrained increases in GHG concentrations could cause large areas of the globe to become too hot to be habitable (Sherwood and Huber 2010).

However, despite the considerable insight that has been gained into the response of hot extremes to elevated radiative forcing, a key issue that has not yet been explored is the timing of emergence of a novel heat regime in which the new minimum is hotter than the baseline maximum. In addition to increasing the occurrence of severe hot events, a permanent transition to an unprecedented heat regime could substantially increase climate-related stresses by requiring systems to tolerate a novel temperature envelope in which the new conditions are hotter than the hottest conditions to which those systems are currently accustomed. The likelihood that such a novel heat regime could emerge in different parts of the globe as $\mathrm{GHG}$ concentrations continue to increase in the coming decades has not yet been constrained.

We therefore seek to quantify the time of emergence of seasonal temperatures that permanently exceed the hottest season of the late 20th century. This quantification is of both scientific and public interest. Climate policy decisions are currently focused in two primary domains: (1) "mitigation", —or avoidance-of increases in GHG concentrations, and (2) "adaptation" to climatic changes that do occur or are expected to occur. Given that extreme heat already causes a broad array of severe impacts on natural and human systems, quantifying how quickly a novel heat regime could emerge in different areas of the globe is important both for determining the "safe" target for mitigation policy and for generating successful climate change adaptation plans, particularly if the emergence is more abrupt than the horizon for effective action in either the mitigation or adaptation domain (Carter et al. 2007).

\section{Methods}

We analyze simulated surface air temperature from the CMIP3 global climate model archive (Meehl et al. 2007a). We analyze a total of 52 realizations of the 24 models that contributed both 20th century and A1B (IPCC W.G.I. 2000) simulations. We focus on 3 metrics of severe heat emergence, calculated separately for June-JulyAugust (JJA) and December-January-February (DJF) surface air temperature: (1) the percentage of seasons warmer than the late 20th century maximum; (2) the "time of emergence" of ensemble exceedence of the late 20th century maximum; and (3) the timing of the last occurrence of a season cooler than the late 20th 
century maximum. These are probabilistic metrics, and we calculate them across the realizations in the CMIP3 ensemble. Following Giorgi and Bi (2005, 2009), we first interpolate each of the CMIP3 realizations to a common 1-degree grid.

For (1), we first calculate the difference between the seasonal temperature and the hottest season of the late 20th century baseline period, at each grid point for each year of each realization. Then, for each 21 st century period, we calculate the total number of seasons in the ensemble that are hotter than the respective late 20th century maximum, and divide by the total number of years in the ensemble during that period.

For (2), we follow Giorgi and Bi (2009) to quantify the date at which the ensemble mean warming above the late 20th century maximum emerges above the ensemble spread (see schematic Fig. S1 illustrating one grid point). First, for each 21st century realization at each grid point, we calculate the difference between the decadalmean seasonal temperature and the maximum seasonal temperature of the late 20th century baseline period, for all possible 21st century decadal averages (i.e. 2000-2009, 2001-2010, ..., 2089-2098). We then identify the last decade in which the ensemblemean difference-from-maximum is less than the standard deviation of the differencefrom-maximum of the individual realizations.

For (3), we apply the time of emergence framework to quantify the date at which the seasonal temperature in each realization permanently exceeds the late 20th century maximum (see Fig. S1). We first calculate the difference between the seasonal temperature and the hottest season of the late 20th century baseline period, at each grid point for each year of each realization. We then identify the last year in which the seasonal mean is less than the late 20th century maximum at each grid point in each realization, and calculate the earliest, 25 th percentile, median, 75 th percentile, and latest values across all realizations. For (2) and (3), we cannot confirm whether the exceedence is permanent beyond the 21 st century, and therefore consider all last exceedences beyond 2080 to be not permanent.

We compare the CMIP3 ensemble simulation of the historical period with the observational dataset of Willmott and Matsuura (2001; version 4.01 (Matsuura and Willmott 2009)). We use 1980-1999 as a late 20th century baseline and 1952-1969 as a mid 20th century baseline (we have also used 1951-1999 as a baseline and find the results to be very similar to those with the 1980-1999 baseline.)

\section{Results and discussion}

\subsection{The global pattern of permanent emergence}

We find that the most immediate increase in extreme seasonal heat occurs in the tropics, with up to $70 \%$ of seasons in the early 21 st century period (2010-2039) exceeding the late 20th century maximum (for both JJA and DJF; Fig. 1). This tropical intensification continues with higher GHG concentrations, including greater than $90 \%$ of seasons exceeding the baseline maximum over most of tropical Africa, tropical South America, and Southeast Asia in the late 21st century (2070-2098). In the extra-tropics, exceedence is generally greater during the summer than the winter, including greater than $90 \%$ over much of extra-tropical Africa, southern Eurasia, and western North America in the late 21st century. The ensemble signal of extreme 


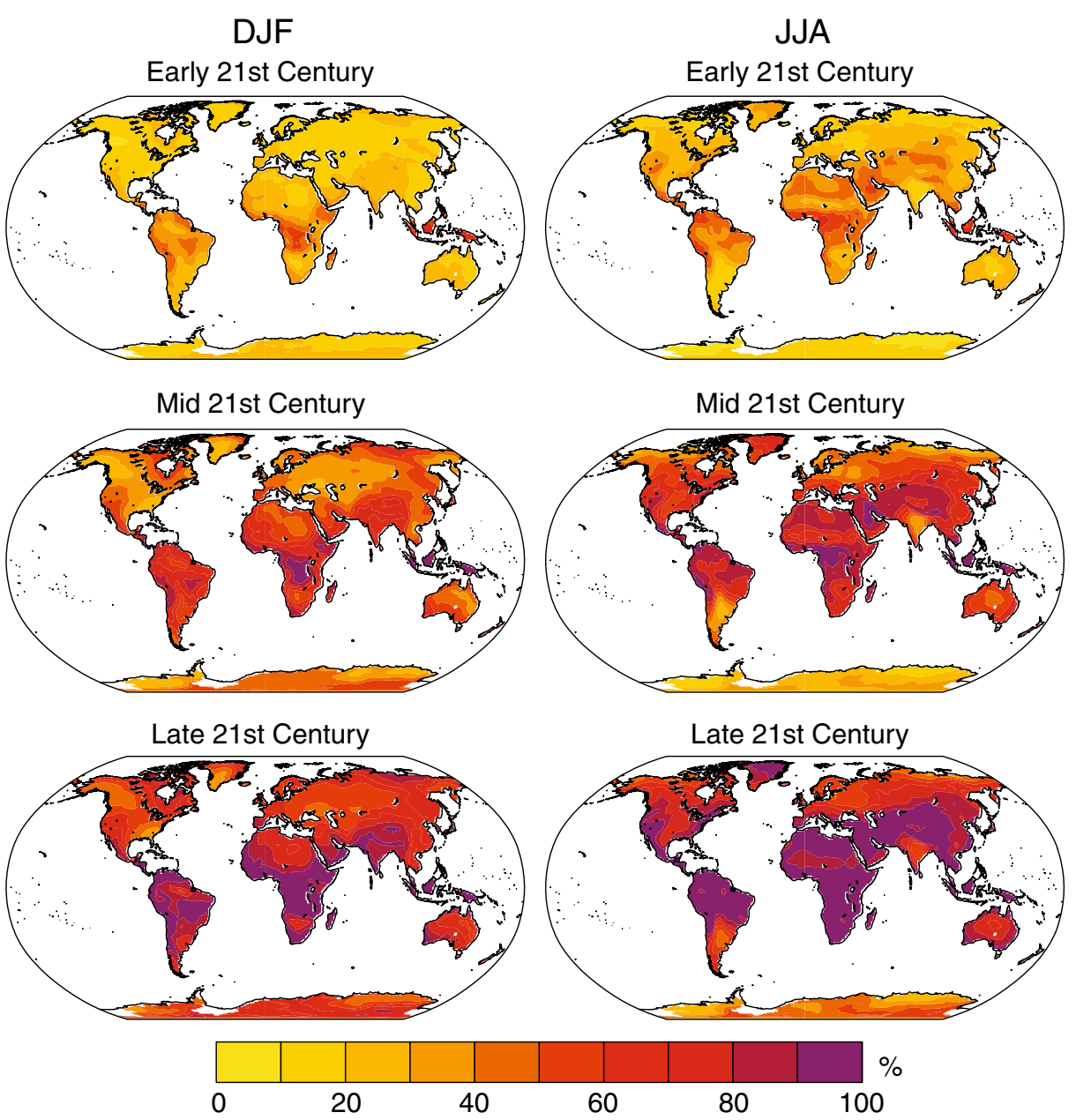

Fig. 1 The percentage of seasons in the CMIP3 A1B ensemble for which the surface air temperature exceeds the warmest season of the 1980-1999 period. The early 20 th century period is $2010-2039$, the mid 20th century period is 2040-2069, and the late 20th century period is 2070-2098

seasonal heat occurrence emerges above one standard deviation of the ensemble spread in the decade of the 2030s over the tropical oceans in JJA and DJF, in the decade of the 2040s over areas of tropical Africa and western South America in JJA and DJF, and in the decade of the 2040s over areas of northern Africa and southern Eurasia in JJA (Fig. 2).

In addition to the time of emergence of a robust signal across the ensemble, we also identify the last season in each model realization that is cooler than that realization's late 20th century maximum. This last occurrence signifies the date of permanent 21 st century exceedence of the baseline maximum in each realization, and the ensemble distribution of dates can be quantified at each grid point from the dates in the individual realizations. The earliest date of permanent exceedence across the ensemble occurs during the first decade of the 21 st century over much 


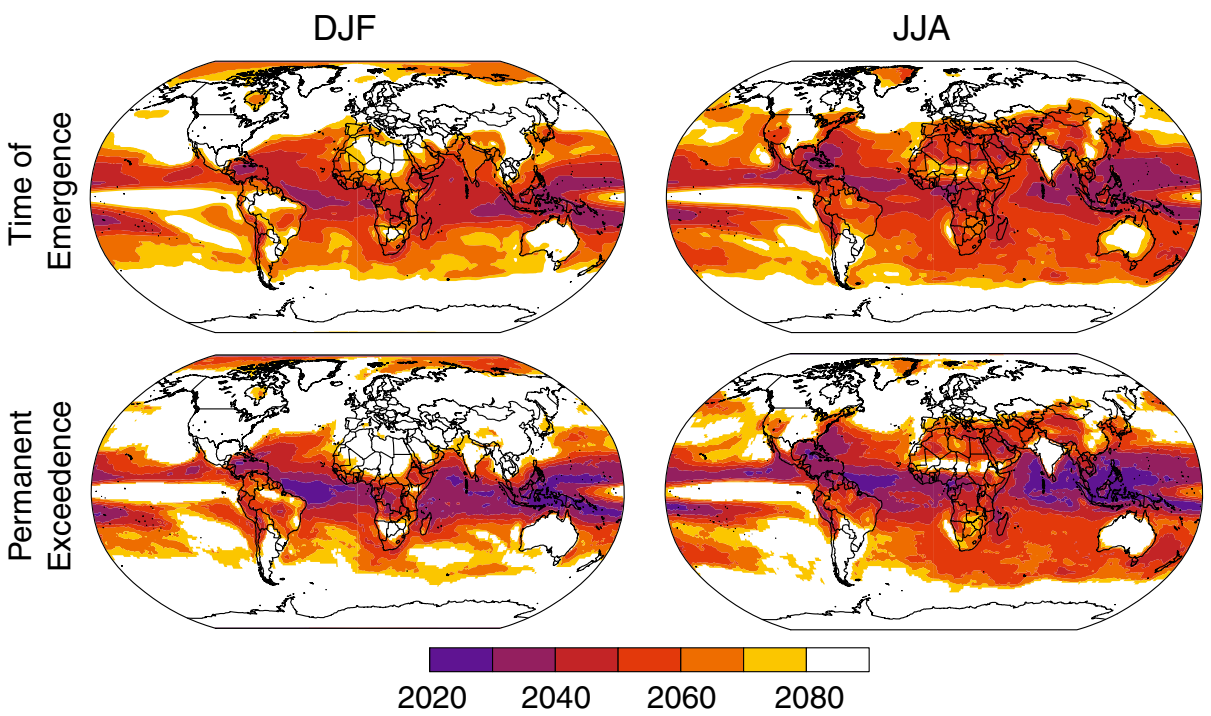

Fig. 2 Decade of emergence of extreme surface air temperature. The top row shows the time of emergence (TOE) of the ensemble signal, calculated as the decade in which the ensemble mean seasonal temperature difference from the 1980-1999 maximum becomes permanently greater than the spread (one standard deviation) between the individual member differences from the 1980-1999 maximum. The second row shows the decade of the last occurrence of a season that is cooler than the 1980-1999 maximum, calculated as the median of the values across the CMIP3 ensemble. We cannot confirm whether the exceedence is permanent beyond the end of the 21st century, and therefore eliminate dates after 2080. Further details of both metrics are given in the text, and in Fig. S1

of the tropics in both seasons, as well as areas of North America, northern Africa, and Eurasia in JJA (Fig. S2). The median date of permanent exceedence occurs by the end of the 2020s over the tropical oceans and parts of tropical Africa, and by the end of the 2050s over most of the tropics and large areas of northern Africa and southern Eurasia (Fig. 2). The 25th percentile permanent exceedence emerges prior to 2060 over large areas of extra-tropical North America, South America, Africa and Eurasia, while the 75th percentile is confined primarily to the tropics prior to 2060 .

\subsection{Regional emergence}

Of the tropical land areas, the regions of Central Africa and Southeast Asia show the most rapid and robust intensification of extreme seasonal heat, with at least $60 \%$ of regional land area exceeding the late 20 th century maximum after the mid2040s in the ensemble mean, and after the mid-2080s in all realizations (for JJA; Figs. 3, S3). The ensemble-mean exceedence increases to greater than $90 \%$ after 2080 over Central Africa, Southern Africa, Southeast Asia and Northern South America in JJA and DJF. The mean JJA exceedence in the extra-tropical regions of North America, China and the Mediterranean is greater than $60 \%$ after 2040 and greater than $80 \%$ after 2080 . However, all three regions exhibit less immediate intensification of extreme seasonal temperature in DJF (with mean exceedence of less than $40 \%$ by 2040 in all three regions), along with much greater variation 


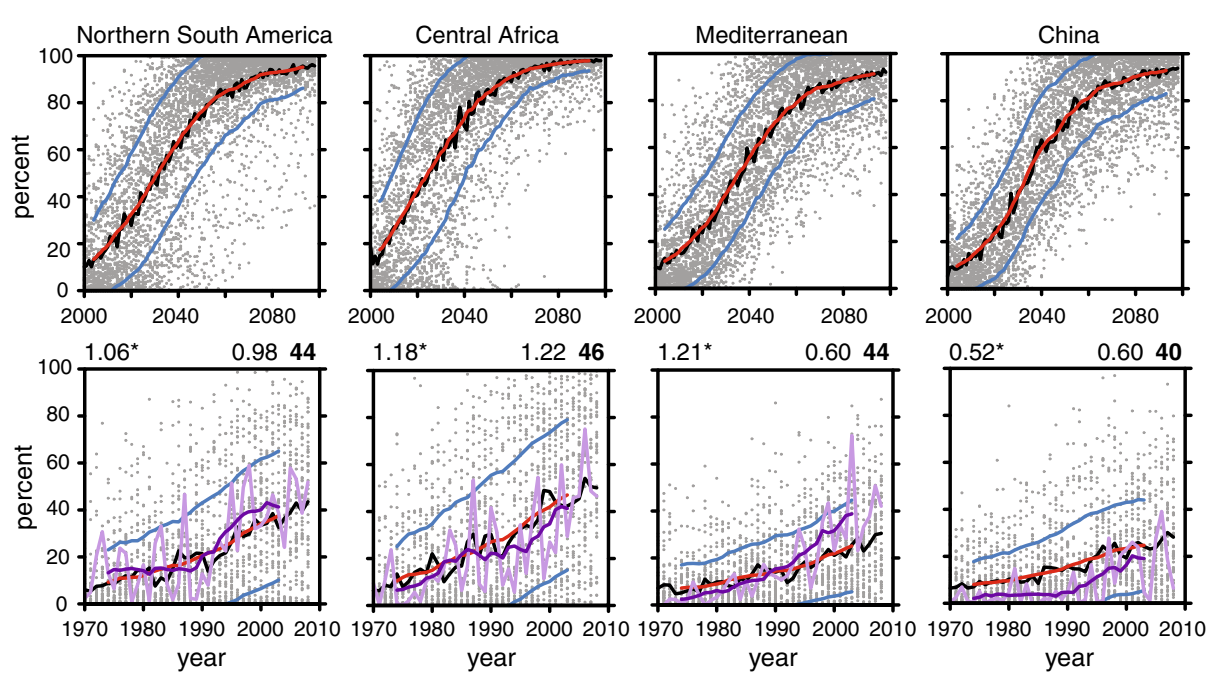

Fig. 3 Time series of exceedence of historical temperature extreme. Top row time series of the fraction of land grid points with JJA surface air temperatures above the respective 19801999 maximum. Bottom row time series of the fraction of land grid points with JJA surface air temperatures above the respective 1952-1969 maximum. The grey points denote this fraction for each CMIP3 model realization. The black curves show the mean across all realizations. The red curves show the 10-year running mean of the mean across all realizations. The blue curves show the 10 -year running mean of a one-standard-deviation range across the mean of all realizations. The light purple curves show the observational timeseries. The dark purple curves show the 10-year running mean of the observational timeseries. The regions cover land areas in Northern South America $\left(25^{\circ} \mathrm{S}-3^{\circ} \mathrm{N}\right.$, $\left.82-33^{\circ} \mathrm{W}\right)$, Central Africa $\left(1^{\circ} \mathrm{S}-13^{\circ} \mathrm{N}, 18^{\circ} \mathrm{W}-51^{\circ} \mathrm{E}\right)$, the Mediterranean $\left(28-50^{\circ} \mathrm{N}, 12^{\circ} \mathrm{W}-38^{\circ} \mathrm{E}\right)$, and China $\left(21-43^{\circ} \mathrm{N}, 97-123^{\circ} \mathrm{E}\right)$. The trend in the observational timeseries (\% per year) is shown in the upper left of the bottom panels, with those trends that are statistically significant identified with a *. The mean of the trends in the CMIP3 realizations is shown in the upper right of the bottom panels, with the number of realizations that exhibit a statistically significant trend shown in bold

in intensification across the CMIP3 ensemble (Fig. S4). In contrast, the northernhemisphere region of India shows more rapid and robust intensification of extreme seasonal heat occurrence in DJF than in JJA (Figs. 1, S2), although both seasons exhibit substantial variation across the CMIP3 ensemble (Figs. S3, S4). The CMIP3 ensemble exhibits greater 21st-century warming over the region in DJF than in JJA (Christensen et al. 2007; Figs. S5, S6), along with greater agreement in the sign of precipitation change (Christensen et al. 2007). In addition, the coupling of the regional temperature and precipitation responses through surface-atmosphere interactions (Ashfaq et al. 2009) suggests that the lack of model agreement in the JJA precipitation response (Christensen et al. 2007; Ashfaq et al. 2009) contributes to the lack of agreement in the JJA surface temperature response, which in turn reduces ensemble emergence in JJA (Fig. 2).

Unprecedented heat emerges most quickly in the tropics despite the fact that the near-term seasonal warming is of similar or greater magnitude in the extra-tropical regions than in the tropical regions (Figs. 4, S5, S6). This tropical intensification results partly from the fact that the late 20th century interannual variability of seasonal temperature is smaller in the tropical regions, decreasing the difference between the mean and maximum of the late 20th century period. For example, very 
Fig. 4 Probability density function (PDF) of JJA surface air temperature anomalies over land for four regions (Mediterranean, China, Northern South America and Central Africa). Each colored $P D F$ represents anomalies for the CMIP3 ensemble for a 2-decade period of the 21st century (relative to the 1980-1999 period). The black lines show the PDF of the differences between the mean and maximum for the 1980-1999 period, with solid black lines showing the CMIP3 values and dashed lines showing the observed values. Regions are as in Fig. 3
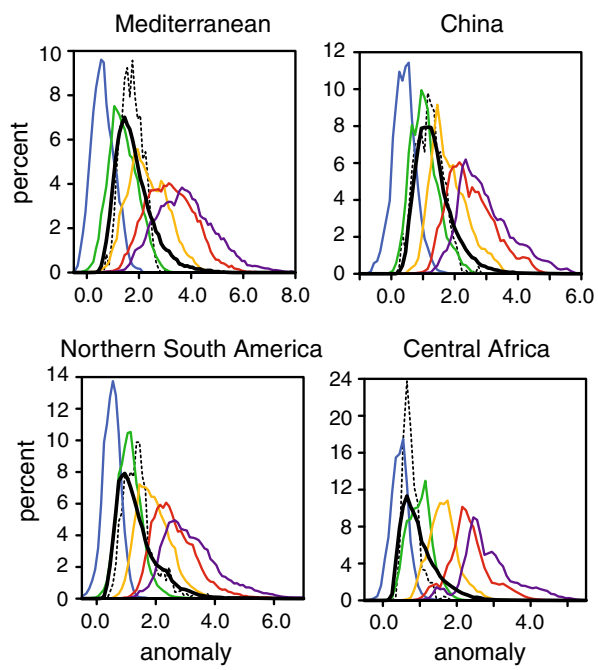

- 2000-2019-2020-2039 - 2040-2059

- 2060-2079 - 2080-2098

few areas of Central Africa and Southeast Asia exhibit late 20th century differences of greater than $2^{\circ} \mathrm{C}$ in JJA, while substantial fractions of North America, China and the Mediterranean exhibit differences of greater than $2^{\circ} \mathrm{C}$ (Figs. 4, S5). Further, North America, China, Southern Africa and the Mediterranean all show smaller interannual variability in summer than in winter (Figs. 4, S5, S6), helping to explain why the emergence of a new temperature regime is more robust in summer than winter in those extra-tropical regions.

\subsection{Observational evidence}

We can use the observed emergence of extreme seasonal heat over the late 20th century and early 21st century to assess the ability of the CMIP3 ensemble to simulate future emergence. Observed temperatures show that the globe and 7 of the 8 regions have experienced statistically significant increases in occurrence of maximum warmseason temperature over the past four decades (relative to a mid 20th century baseline; Figs. S7, S8). The CMIP3 ensemble mean underestimates the observed global emergence for both JJA and DJF, while the ensemble-mean emergence is very similar to that seen in warm-season observations over Central Africa, Southern Africa, Northern South America, India, China and the Mediterranean (Figs. S7, S8). Alternatively, the simulated intensification is too strong over Southeast Asia in JJA and DJF, and over North America in JJA.

The CMIP3 ensemble also captures the primary features of the probability distribution of differences between late 20th century mean and maximum seasonal temperature for both JJA and DJF (Figs. 4, S5, S6). However, biases in the CMIP3 distributions likely influence the simulated future emergence of extreme heat over some regions. For instance, the warm tail of the distribution is wider than observed in JJA over Central Africa, China, and the Mediterranean (Fig. 4). This model bias will serve to artificially decrease the intensification of extreme heat occurrence in 
response to a given seasonal warming, as greater warming is required to exceed the baseline maximum in the CMIP3 ensemble than in reality. Likewise, over India, much of the CMIP3 probability distribution is greater than the observed maximum (Fig. S5), suggesting that the region could in fact see emergence of extreme heat in response to global warming, despite the lack of robust emergence in the CMIP3 ensemble. Conversely, the CMIP3 ensemble under-represents the frequency of grid points with large difference between mean and maximum baseline seasonal temperature over Southeast Asia (Figs. S5, S6). This model bias will serve to artificially increase the exceedence of the late 20th century maximum for a given seasonal warming, as is suggested by the comparison of the CMIP3 suite with observed emergence of extreme heat over Southeast Asia (Figs. S7, S8).

\subsection{Ensemble analysis}

We have focused on the A1B scenario because it allows us to maximize the number of models and individual realizations available for analysis (Meehl et al. 2007b). While the A1B scenario represents just one possible 21st century emissions pathway, the other illustrative SRES scenarios exhibit similar GHG concentrations through the mid-21st century (IPCC W.G.I. 2000; Meehl et al. 2007b). In addition, we have presented the distribution of values across the CMIP3 ensemble, treating each model realization equally. Although we have found that repeating the analyses with just one realization from each model yields very similar results as those presented here, a wide range of alternative treatments of the multi-model ensemble exists (Knutti et al. 2010). The forthcoming CMIP5 multi-model ensemble will provide enhanced opportunities for quantifying the likelihood of near-term emergence of unprecedented heat, particularly given the availability of near-term "decadal prediction" experiments that assimilate ocean observations (Taylor et al. 2009).

\section{Conclusions}

Our analyses of observational data and the current generation of global climate models carry a number of important implications. First, imminent, permanent emergence of unprecedented heat in the tropical regions is likely to result in substantial human impact, particularly given previous humanitarian crises associated with severe heat (Battisti and Naylor 2009), and the synergies between environmental and development challenges (UNDP 2007). Second, the fact that areas of the United States, Europe and China also show permanent emergence by the mid-21st century highlights the fact that nations with developed and emerging economies are also likely to face unprecedented climate stresses even with the relatively moderate warming expected over the next half-century (Meehl et al. 2007b). The fact that global climate models are able to capture the observed intensification of extreme heat globally and over many regions strengthens confidence in the model projections. However, where model biases do exist, they predominantly serve to decrease occurrence of unprecedented heat. Further, actual GHG emissions over the early 21st century have exceeded those projected in the SRES scenario used here (Raupach et al. 2007), suggesting that our results could provide a conservative projection of the timing of permanent emergence of an unprecedented heat regime. 
Acknowledgements We acknowledge the modeling groups, PCMDI, the WCRP's WGCM, and the U.S. DOE for their roles in making the CMIP3 dataset available. The data were analyzed using computing resources provided by the Center for Computational Earth and Environmental Science (CEES) at Stanford University. Our work was supported by NSF award 0955283, DOE award DE-FG02-08ER64649, NIH award S0183091, and the World Bank TFESSD.

Open Access This article is distributed under the terms of the Creative Commons Attribution Noncommercial License which permits any noncommercial use, distribution, and reproduction in any medium, provided the original author(s) and source are credited.

\section{References}

Ashfaq M et al (2009) Suppression of south Asian summer monsoon precipitation in the 21st century. Geophys Res Lett 36:L01704. doi:10.1029/2008GL036500

Battisti DS, Naylor RL (2009) Historical warnings of future food insecurity with unprecedented seasonal heat. Science 323(5911):240-244

Carter TR et al (2007) New assessment methods and the characterisation of future conditions. In: Parry ML et al (eds) Climate change 2007: impacts, adaptation and vulnerability. Contribution of Working Group II to the Fourth Assessment Report of the Intergovernmental Panel on Climate Change. Cambridge University Press, Cambridge, pp 133-171

Christensen JH et al (2007) Regional climate projections. In: Solomon S et al (eds) Climate change 2007: the physical science basis. Contribution of Working Group I to the Fourth Assessment Report of the Intergovernmental Panel on Climate Change. Cambridge University Press, Cambridge

Ciais $\mathrm{P}$ et al (2005) Europe-wide reduction in primary productivity caused by the heat and drought in 2003. Nature 437(7058):529-533

Clark RT, Murphy JM, Brown SJ (2010) Do global warming targets limit heatwave risk? Geophys Res Lett 37. doi:10.1029/2010GL043898

Diffenbaugh NS, Ashfaq M (2010) Intensification of hot extremes in the United States. Geophys Res Lett 37:L15701. doi:10.1029/2010GL043888

Giorgi F, Bi X (2005) Updated regional precipitation and temperature changes for the 21st century from ensembles of recent AOGCM simulations. Geophys Res Lett 32:L21715. doi:10.1029/2005GL024288

Giorgi F, Bi X (2009) Time of emergence (TOE) of GHG-forced precipitation change hot-spots. Geophys Res Lett 36:L06709. doi:10.1029/2009GL037593

IPCC W.G.I. (2000) Special report on emissions scenarios. In: Nakicenovic N, Swart R (eds) Intergovernmental panel on climate change special reports on climate change. Cambridge University Press, Cambridge, p 570

Knutti R et al (2010) Challenges in combining projections from multiple climate models. J Climate 23(10):2739-2758

Matsuura K, Willmott CJ (2009) Terrestrial air temperature: 1900-2008 gridded monthly time series (version 2.01). http://climate.geog.udel.edu/ climate/html_pages/Global2_Ts_2009/README. global_t_ts_2009.html

Meehl GA et al (2007a) Global climate projections. In: Solomon S et al (eds) Climate change 2007: the physical science basis. Contribution of Working Group I to the Fourth Assessment Report of the Intergovernmental Panel on Climate Change. Cambridge University Press, Cambridge

Meehl GA et al (2007b) The WCRP CMIP3 multimodel dataset-a new era in climate change research. Bull Am Meteorol Soc 88(9):1383-1394

Patz JA et al (2005) Impact of regional climate change on human health. Nature 438(7066):310-317

Poumadere $\mathrm{M}$ et al (2005) The 2003 heat wave in France: dangerous climate change here and now. Risk Anal 25(6):1483-1494

Raupach MR et al (2007) Global and regional drivers of accelerating CO2 emissions. Proc Natl Acad Sci 104(24):10288-10293

Schlenker W, Roberts MJ (2009) Nonlinear temperature effects indicate severe damages to US crop yields under climate change. Proc Natl Acad Sci USA 106(37):15594-15598

Sherwood SC, Huber M (2010) An adaptability limit to climate change due to heat stress. Proc Natl Acad Sci USA 107(21):9552-9555 
Taylor KE, Stouffer RJ, Meehl GA (2009) A summary of the CMIP5 experimental design, 18 December 2009. PCMDI, Lawrence Livermore National Laboratory, Livermore, p 32

UNDP (2007) Human Development Report 2007/2008: fighting climate change: human solidarity in a divided world. Palgrave Macmillan for the United Nations Development Programme, New York, NY, p 384

UNFCCC (2009) The Copenhagen Accord. Fifteenth session, Copenhagen, 7-18 December 2009, vol FCCC/CP/2009/L.7. The United Nations, p 5

White MA et al (2006) Extreme heat reduces and shifts United States premium wine production in the 21st century. Proc Natl Acad Sci 103(30):11217-11222

Willmott CJ, Matsuura K (2001) Terrestrial air temperature and precipitation: monthly and annual time series (1950-1999). University of Delaware. http://climate.geog.udel.edu/ climate/html_ pages/air_ts2.html 